\title{
Reactive Pulsed Laser Deposition of Titanium Nitride Thin Films: Effect of Reactive Gas Pressure on the Structure, Composition, and Properties
}

\author{
R. Krishnan, ${ }^{1}$ C. David, ${ }^{1}$ P. K. Ajikumar, ${ }^{1}$ R. Nithya, ${ }^{1}$ S. Tripura Sundari, ${ }^{1}$ S. Dash, ${ }^{1}$ \\ B. K. Panigrahi, ${ }^{1}$ M. Kamruddin, ${ }^{1}$ A. K. Tyagi, ${ }^{1}$ Vikram Jayaram, ${ }^{2}$ and Baldev Raj ${ }^{3}$ \\ ${ }^{1}$ Materials Science Group, Indira Gandhi Centre for Atomic Research, Kalpakkam, Tamil Nadu 603102, India \\ ${ }^{2}$ Department of Materials Engineering, Indian Institute of Science, Bangalore, Karnataka 560012, India \\ ${ }^{3}$ President, PSG Institutions, Coimbatore, Tamil Nadu 641004, India \\ Correspondence should be addressed to R. Krishnan; krish@igcar.gov.in
}

Received 19 November 2012; Accepted 13 December 2012

Academic Editor: Ram Gupta

Copyright ( 92013 R. Krishnan et al. This is an open access article distributed under the Creative Commons Attribution License, which permits unrestricted use, distribution, and reproduction in any medium, provided the original work is properly cited.

Titanium nitride (TiN) thin films were deposited by reactive pulsed laser deposition (RPLD) technique. For the first time, the composition evaluated from proton elastic backscattering spectrometry, in a quantitative manner, revealed a dependence on the partial pressure of nitrogen from 1 to $10 \mathrm{~Pa}$. Grazing incidence-XRD (GI-XRD) confirmed the formation of predominantly nanocrystalline TiN phase with a crystallite size of around $30 \mathrm{~nm}$. The hardness showed maximum value of $\sim 30 \mathrm{GPa}$ when the composition is near stoichiometric and the friction coefficient was found to be as low as 0.3. In addition, a systematic optical response was observed as a function of deposition pressure from the surface of the TiN films using spectroscopic ellipsometry.

\section{Introduction}

Titanium nitride (TiN), by virtue of its high hardness, high melting point, low density, chemical stability, corrosion resistance, low coefficient of friction, lower wear rate, and so forth, is the most extensively used protective coating material [1-4]. All these properties depend on the coating techniques and vary as a function of deposition conditions. Amongst the gamut of available techniques, reactive pulsed laser deposition (RPLD) has distinct advantages to deposit ceramic films using metallic targets.

Despite large volume of published work on TiN synthesis using RPLD, none brings out a clear recipe for synthesizing high-quality TiN films with desired stoichiometry, structure and morphology. For many applications, quantitative evaluation of the composition is very essential as the properties of TiN are closely related to its stoichiometry [1]. Till date there is only one research article that attempted to study the systematic evolution of structure in RPLD grown TiN films and a review article which summarized those results was published in 2002 [5, 6]. Even that article did not report quantitative compositional variation with nitrogen pressure and proposed the deposition of nanocrystalline TiN films over a range of deposition pressures $(0.7$ to $7 \mathrm{~Pa})$ without accounting for the finer variations in the given range. In fact, the ellipsometry was used in-situ by Heil et al. to monitor, in-situ, the thickness of the films rather than to characterize the optical properties [7]. Though qualitative, in a recent work, we presented a novel secondary-ion-massspectrometry (SIMS) based methodology for optimization of three important process parameters, namely, deposition pressure, substrate temperature and pulse energy [8]. As relative sensitivity of elemental factors arising from the matrix effects are little known, obtaining quantitative estimates of the elemental composition from SIMS data is difficult.

In this study, we present the systematic evolution of structure through grazing incident X-ray diffraction (GIXRD) analysis and quantitative composition variation of RPLD grown TiN films as a function of deposition pressure in the range of 1.0 to $10.0 \mathrm{~Pa}$ using proton elastic back scattering 
(PEBS) spectrometry. PEBS is superior to the conventional Rutherford backscattering spectrometry (RBS) using alpha particles, especially for analyzing low Z elements embedded or present as films on higher $Z$ substrates [9]. In the particular case of obtaining compositional information of TiN using conventional RBS it is imperative to deposit these films on a lower Z substrate (usually a carbon/silicon substrate). But the application of PEBS facilitates determination of composition of the TiN films coated over the structural material itself [AISI 304 SS]. In the present study, the effect of deposition pressure in influencing the structure, composition, and morphology of TiN films is addressed.

\section{Experimental}

A complete description of the experimental facility is given in our earlier publication [10]. A Q-switched Nd:YAG laser, operating at $1064 \mathrm{~nm}$ with a fluence of $4 \mathrm{~J} / \mathrm{cm}^{2}$ and $10 \mathrm{~Hz}$ repetition rate, was introduced into an ultra-high vacuum (UHV) compatible reaction chamber through a quartz window and was focused to approximately $2 \mathrm{~mm}$ diameter circular spot at the target surface at an oblique incidence of $45^{\circ}$. The laser pulse duration was $5 \mathrm{~ns}$. A titanium disc of $24.5 \mathrm{~mm}$ diameter, $10 \mathrm{~mm}$ thickness, and having purity of 99.9\% was used as a target. The target was rotated at $3 \mathrm{rpm}$ to prevent crater formation and to expose fresh material for laser ablation. Prior to deposition, the AISI 304 SS substrates (20 mm diameter $\times 3 \mathrm{~mm}$ thick) were degreased, cleaned, and dried. Part of the ablating plume was made to deposit on the substrates positioned on a substrate heater, located just in front of the target. A target-substrate distance of $40 \mathrm{~mm}$ was maintained during the deposition, and 1,00,000 laser pulses were fired to get approximately $1 \mu \mathrm{m}$ thick coatings. The chamber was evacuated to a base pressure of $5.0 \times$ $10^{-5} \mathrm{~Pa}$ using a turbomolecular pumping system. Ultra-high pure $\mathrm{N}_{2}$ gas was bled into the chamber using a mass flow controller. The coatings were characterized for structural, compositional, and morphological information by GIXRD, PEBS, and AFM, respectively. Hardness of the coatings was evaluated by nanoindentation. The optical studies were carried out using a SOPRA ESVG model rotating-polarizertype ellipsometer in the energy range 1.38 to $5 \mathrm{eV}$ at an angle of incidence of 75 degree. Low-load (25-100 $\mathrm{mN}$ range) friction and wear measurement were carried out using a nanotribometer (M/s CSM Instruments, Switzerland).

\section{Results and Discussion}

3.1. Structural Determination. The GIXRD patterns of the $\mathrm{TiN}_{x}$ films, deposited on SS substrates with a constant pulse energy and substrate temperature, are shown in Figure 1. The nitrogen pressure inside the chamber was varied from 1 to $10 \mathrm{~Pa}$ in 5 steps. But for the small fraction of $\mathrm{Ti}_{2} \mathrm{~N}, \mathrm{TiON}$, and $\mathrm{TiO}_{2}$ phases, all the patterns indicated the formation of single-phase cubic TiN (space group: Fm $\overline{3} \mathrm{~m}$ ) with a lattice parameter of $4.234 \AA$. This is in agreement with the JCPDS data file: $38-1420$. While the films deposited at lower pressures $(\leq 3 \mathrm{~Pa})$ showed the presence of $\mathrm{Ti}_{2} \mathrm{~N}$, deposition at
TABle 1: Composition of TiN thin films as measured using PEBS.

\begin{tabular}{lcc}
\hline Deposition pressure $P_{\mathrm{N}_{2}}(\mathrm{~Pa})$ & $\mathrm{N}_{\mathrm{N}} / \mathrm{N}_{\mathrm{T}_{\mathrm{j}}}$ & $\mathrm{N}_{0} / \mathrm{N}_{\mathrm{T}_{\mathrm{j}}}$ \\
\hline 1.0 & 0.44 & 0.56 \\
3.0 & 0.82 & 0.18 \\
5.0 & 0.90 & 0.10 \\
7.0 & 0.76 & 0.24 \\
10.0 & 0.59 & 0.41 \\
\hline
\end{tabular}

higher pressures (above $5 \mathrm{~Pa}$ ) indicates the incorporation of oxygen into TiN leading to the formation of $\mathrm{TiON}$ or even $\mathrm{TiO}_{2}$. At higher pressures, even a small increase of oxygen in the background gas leads to a preferential formation of oxides and oxynitrides as reported in literature $[5,11]$. Formation of nearly stoichiometric and polycrystalline TiN is observed for films deposited at around $\sim 5 \mathrm{~Pa}$. Thus the XRD patterns confirm the formation of stoichiometric TiN by RPLD process and the presence of minor amount of $\mathrm{Ti}_{2} \mathrm{~N}$ and TiON phases. The crystallite size was evaluated from (200) peak using the Scherer formula and found to be around $28 \mathrm{~nm}$ for all the films.

3.2. Compositional Evaluation. The proton backscattering studies ${ }^{14} \mathrm{~N}(\mathrm{p}, \mathrm{p}){ }^{14} \mathrm{~N}$ were carried out at an incident proton energy of $2.0 \mathrm{MeV}$ so as to utilize a energy regime with enhanced scattering cross section [9]. The proton backscattering studies are standardized by obtaining the composition of a bulk TiN compound. The experimental spectrum obtained for the bulk TiN was simulated using SIMNRA program [12], and it is found that the estimated composition is in agreement with the certified value. The PEBS spectra and the fits obtained using SIMNRA for the $\mathrm{TiN}_{x}$ films deposited at $7 \mathrm{~Pa}$ are shown in Figure 2(a). The various edges (Ti, substrate, $\mathrm{O}$ and $\mathrm{N}$ ) are indicated. To obtain the quantitative estimates, the experimental spectrum is simulated using the SIMNRA code [12].

Cumulative composition of the films as a function of deposition pressure was computed, and the results are tabulated in Table 1. The tabulation clearly indicates the trend in the N/Ti ratio. For the film deposited at $5 \mathrm{~Pa}$, the $\mathrm{N} / \mathrm{Ti}$ ratio approaches stoichiometry and then drops. Oxygen incorporation in titanium nitride films could be reasoned as follows: titanium rich films deposited at lower nitrogen pressures pickup more oxygen when exposed to air than stoichiometric TiN films. But at higher deposition pressures the quantity of impurity oxygen increases, and hence its incorporation is more.

3.3. Morphological Investigations. The surface morphology was analyzed using AFM over an area of $5 \times 5 \mu \mathrm{m}$ and the results are shown in Table 2 . The films grown at $\sim 1 \mathrm{~Pa}$ revealed RMS roughness of $1.9 \mathrm{~nm}$. Large number of particles with average diameter of $100-200 \mathrm{~nm}$ were found to be distributed. At low pressures, the incoming plume will have high energy with high mean free path leading to high flux and nonuniformity. With increase in background pressure, the incoming flux gets thermalized due to decrease in mean free 


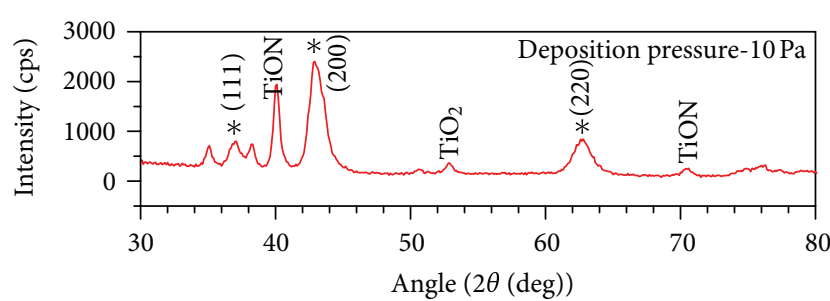

(a)

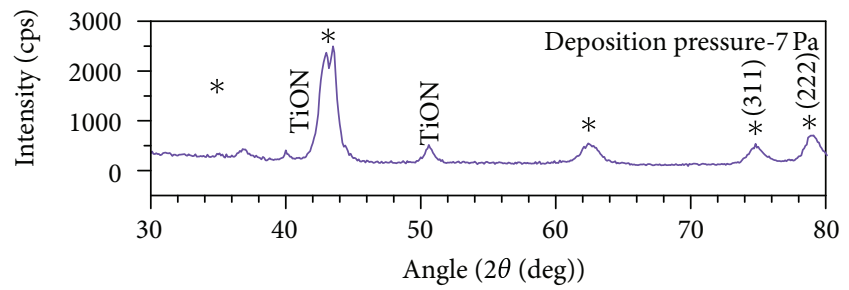

(b)

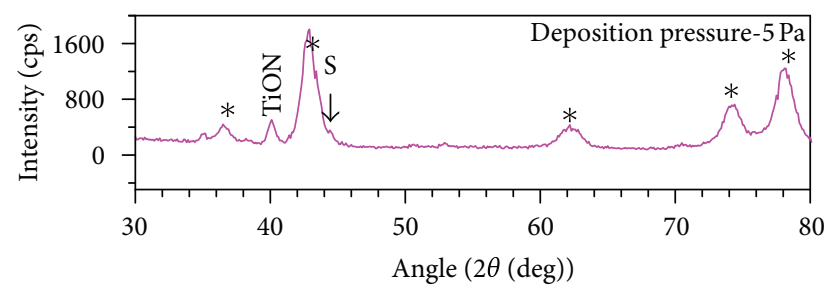

(c)

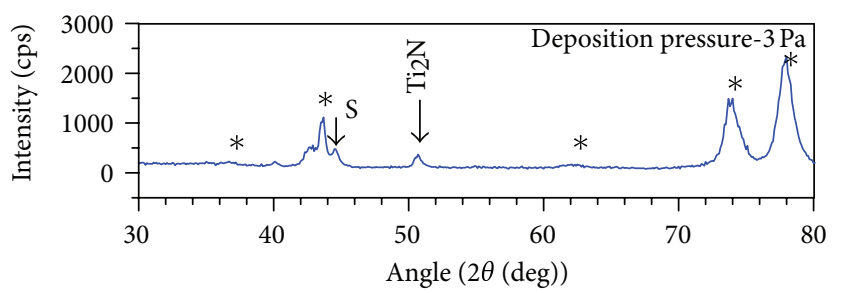

(d)

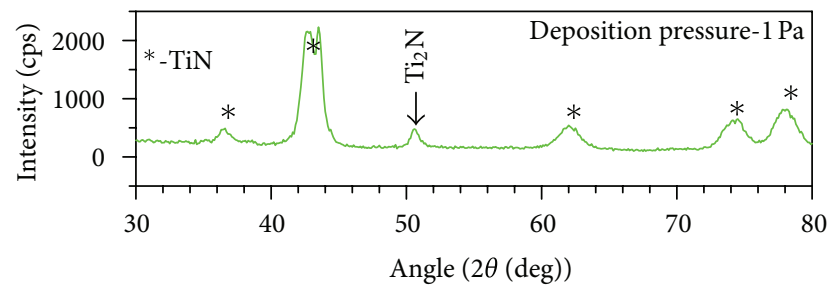

(e)

Figure 1: X-ray diffraction patterns of TiN films deposited at different nitrogen pressures. $(*)$ and $(S)$ denote peaks due to TiN and SS substrate, respectively.

path. This leads to coalescence of the particles leading to fewer and bigger particles. Hence the RMS roughness value at $3 \mathrm{~Pa}$ increases to $2.2 \mathrm{~nm}$ and then further rises to $6.6 \mathrm{~nm}$ at $5 \mathrm{~Pa}$. However, at $7 \mathrm{~Pa}$, due to the increased availability of nitrogen and the collision events, the number of particles reaching the surface reduces leading to the reduction in both number density and their average height leading to reduction in RMS roughness to $4.3 \mathrm{~nm}$. Figure 2(b) shows the representative

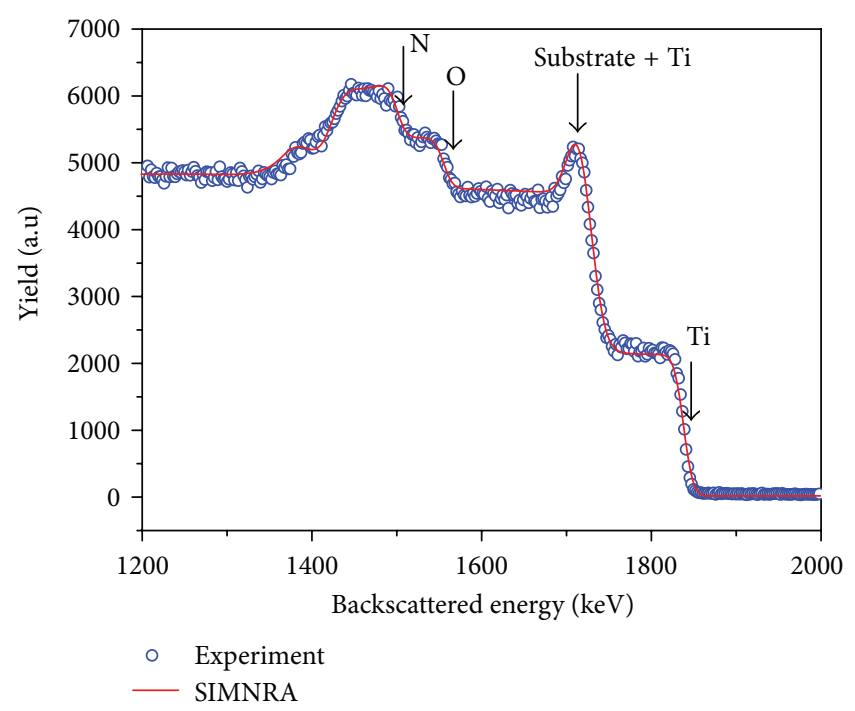

(a)

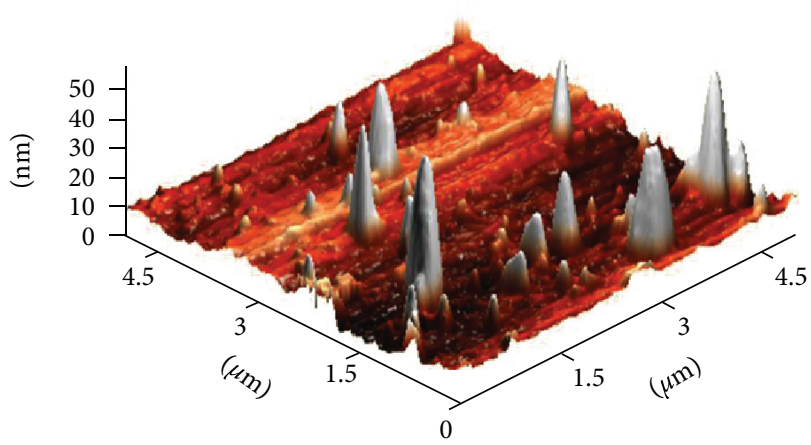

(b)

Figure 2: (a) PEBS spectra and (b) AFM image of TiN films grown at $7 \mathrm{~Pa}$.

TABLE 2: Roughness of the films as measured from AFM.

\begin{tabular}{lc}
\hline Deposition pressure $(\mathrm{Pa})$ & RMS roughness $(\mathrm{nm})$ \\
\hline 1.0 & 1.9 \\
3.0 & 2.2 \\
5.0 & 6.6 \\
7.0 & 4.5 \\
10.0 & 4.3 \\
\hline
\end{tabular}

AFM image of TiN films grown at $7 \mathrm{~Pa}$. This trend continues for the deposition pressure of $10 \mathrm{~Pa}$.

3.4. Optical Properties. A qualitative behavior of the optical response of the films grown at different partial pressures is presented. The real part of the dielectric functions for specimens deposited between $1 \mathrm{~Pa}$ to $7 \mathrm{~Pa}$ is shown in Figure 3 (a). From the figure, it is seen that the magnitude of the real part of the dielectric function $\left\langle\varepsilon_{1}\right\rangle$ increases with increase in partial pressure of nitrogen, varying from $\sim-5 @ 1.5 \mathrm{eV}$ for $1 \mathrm{~Pa}$ to $\sim 0.2 @ 1.5 \mathrm{eV}$ for $7 \mathrm{~Pa}$. The plasma frequency of 
the films is 2.37 and 2.09 (energy at which $\varepsilon_{1}=0$ ) for films deposited at $1 \mathrm{~Pa}$ and $3 \mathrm{~Pa}$, respectively. The typical value of $\left\langle\varepsilon_{1}\right\rangle @ 1.5 \mathrm{eV}$ and plasma frequency for a reference TiN is typically -15 and 2.7 , respectively. The increase in $\left\langle\varepsilon_{1}\right\rangle$ and plasma frequency is attributed to the formation of $\mathrm{TiO}_{2}$ which is semiconducting and has a band gap of $\sim 3.2 \mathrm{eV}$. For the film deposited at $5 \mathrm{~Pa}$, the material is predominantly $\mathrm{TiO}_{2}$ (more than 50\%). It is to be pointed out that, in ellipsometry, the thickness that is probed depends on the material and is typically $100 \mathrm{~nm}$ for the TiN owing to its metallic nature. The percentages obtained from ellipsometry cannot be compared one to one with that obtained from PEBS as PEBS probes deeper into the film. The refractive indices shown in Figure 3(b) differ from that reported by Jeyachandran et al. [13] for very low nitrogen concentration. The film shows an evolution towards $\mathrm{TiO}_{2}$-rich phase with increase in partial pressure of nitrogen. A clear systematic evolution is seen in the optical properties and indicates the potential for being used insitu to characterize the relation between stoichiometry and thickness [14].

3.5. Hardness. In order to evaluate the hardness of these TiN coatings, samples were subjected to nanoindentation. Figure 4 shows the results of nanohardness measurements of a series of TiN coatings deposited at room temperature on a AISI-SS-304 substrates with a total thickness of $1 \mu \mathrm{m}$. The nanohardness of TiN samples reaches its maximum at the deposition pressure of 3-5 $\mathrm{Pa}$ and then decreases at higher deposition pressures. It is interesting to note that average hardness values of films deposited at around 3-5 Pa are greater than the hardness values of other deposition pressure in concomitant with the PEBS results showing higher nitrogen content with $\mathrm{N}_{\mathrm{N}} / \mathrm{N}_{\mathrm{Ti}}$ values greater than 0.8 , whereas the hardness values are lower for the higher oxygen values.

3.6. Tribological Properties. Figure 5 depicts the typical curves showing the variation of coefficient of friction (COF) with two different speeds and two different loads when the $100 \mathrm{Cr} 6$ steel ball was made to slide on the RPLD grown TiN films deposited at $3 \mathrm{~Pa}$. At low speed $(0.1 \mathrm{~m} / \mathrm{sec})$ and low load $(100 \mathrm{mN})$, the surface regenerates itself after initial break down as revealed by the rapid rise in COF followed by a steady decline. But at higher load $(700 \mathrm{mN})$, for the same speed of $(0.1 \mathrm{~m} / \mathrm{sec})$, the COF falls initially due to smoothening of surface asperities followed by steady increase due to compound wear that consequently enhances COF. With the passage of laps, the surface gets smoothened, and hence there is a fall in COF which again rises much more steeply due to the faster wear rates coupled with smoothening. However, at higher speeds $(0.5 \mathrm{~cm} / \mathrm{sec})$, a cyclic pattern in the variation of COF is observed for both the loads (100 and $700 \mathrm{mN})$, though with different periodicity.

\section{Conclusions}

Studies have been carried out on the synthesis of nanocrystalline TiN thin films using RPLD through ablation of

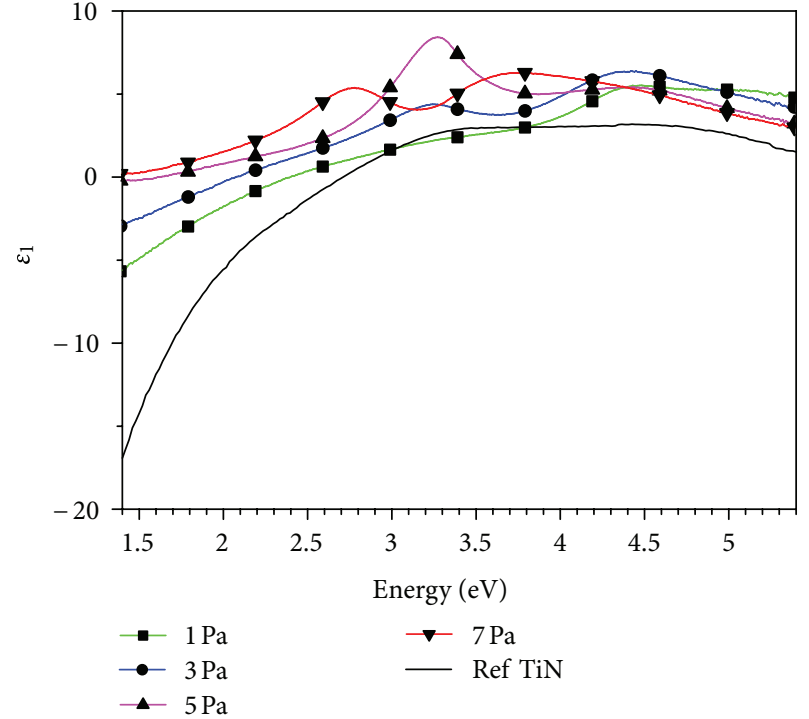

(a)

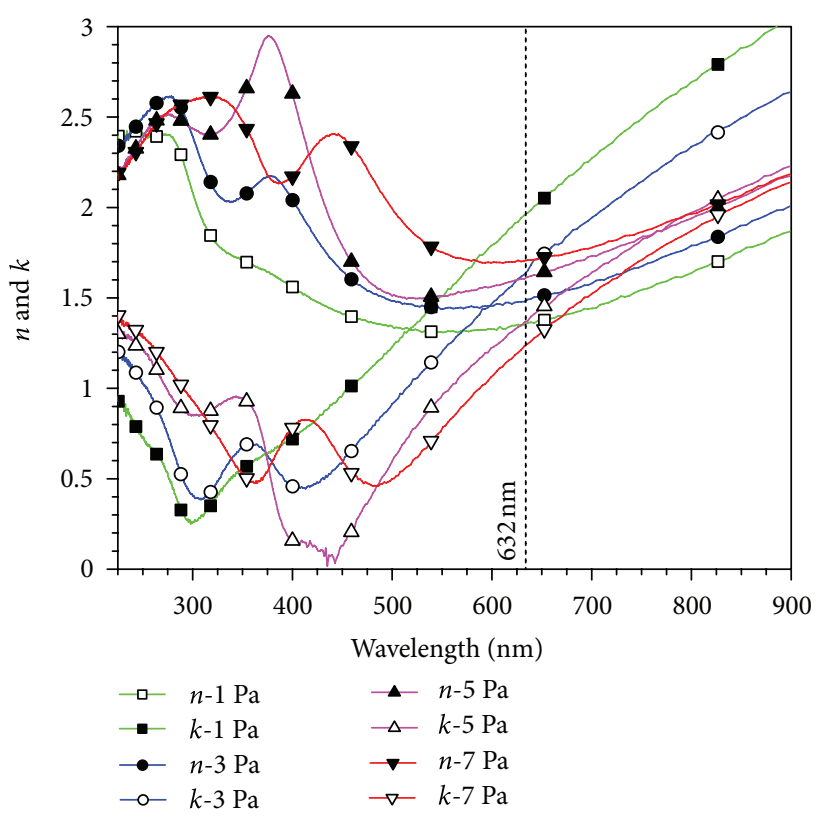

(b)

Figure 3: (a) Real part $\left(\varepsilon_{1}\right)$ and (b) Refractive index ( $n$ and $k$ ) for specimen deposited at different nitrogen pressures.

high purity titanium targets in the presence of low-pressure nitrogen gas, with constant temperature and laser power using Nd:YAG laser operating at $1064 \mathrm{~nm}$. Films were characterized using GIXRD, PEBS, and AFM for their structure, composition, and morphology, respectively. Ellipsometric and hardness measurements indicated a systematic evolution in both optical and mechanical properties. Results reveal that deposition pressure is crucial for obtaining desired stoichiometry. Nanocrystalline TiN close to stoichiometry was obtained for the film deposited with nitrogen pressure of 3-5 $\mathrm{Pa}$ with maximum hardness values as measured using nanoindentation. Also, the friction coefficient of the TiN 


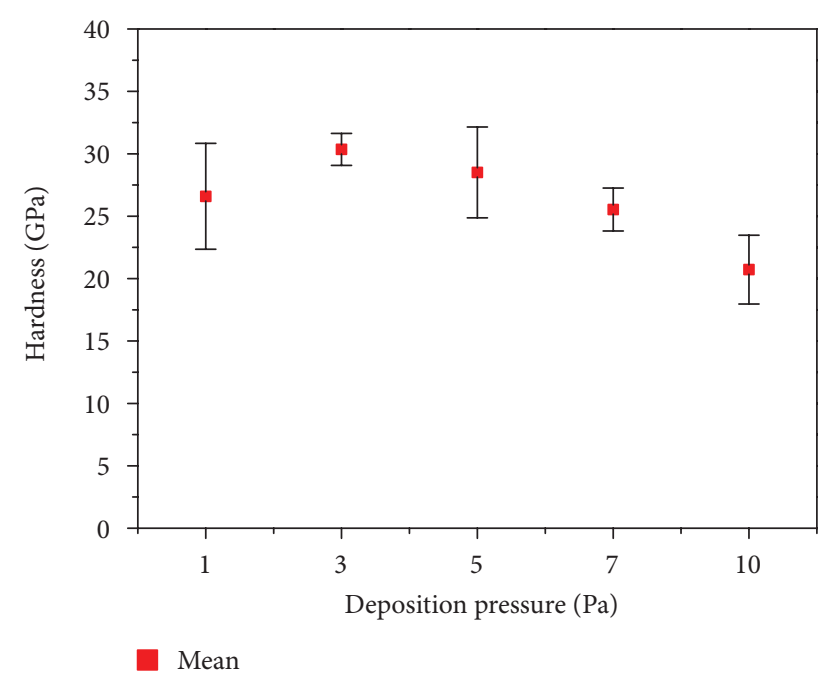

FIGURE 4: Hardness of the TiN films deposited at different nitrogen pressures.

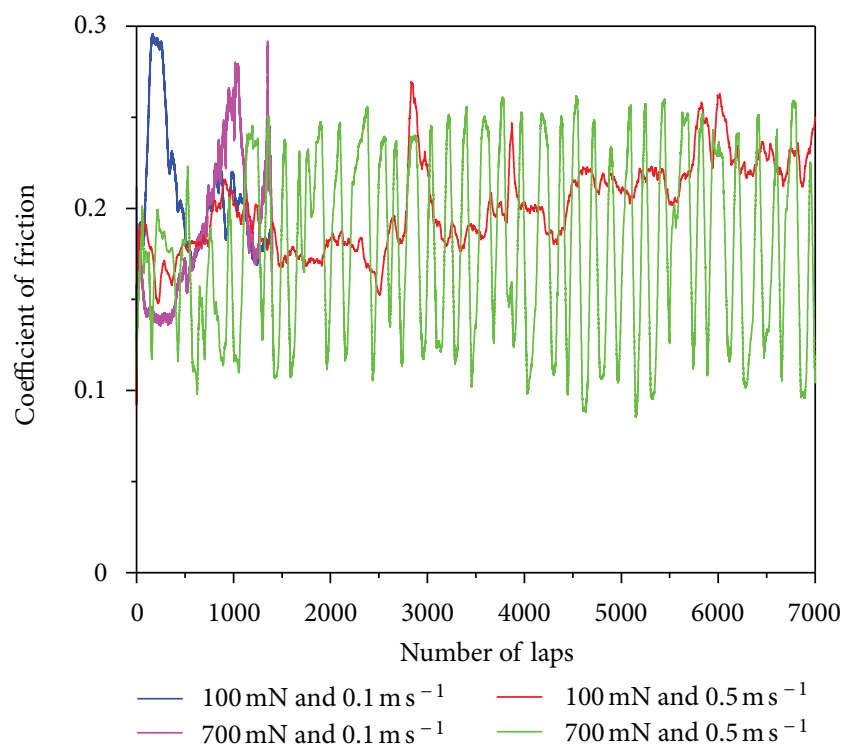

Figure 5: Variation of COF of monolithic TiN thin film deposited at $3 \mathrm{~Pa}$ under variable loads and speeds.

films, deposited by RPLD, was found to be low as compared to that of their microcrystalline counterparts.

\section{References}

[1] J. E. Sundgren, "Structure and properties of TiN coatings," Thin Solid Films, vol. 128, no. 1-2, pp. 21-44, 1985.

[2] P. Ettmayer and W. Lenguer, "Transition metal nitrides: solid state chemistry," in Encyclopedia of Inorganic Chemistry, R. B. King, Ed., John Wiley \& Sons, 2nd edition, 1994.

[3] H. Randhawa, "Hard coatings for decorative applications," Surface and Coatings Technology, vol. 36, no. 3-4, pp. 829-836, 1988.
[4] C. Subramanian and K. N. Strafford, "Review of multicomponent and multilayer coatings for tribological applications," Wear, vol. 165, no. 1, pp. 85-95, 1993.

[5] I. N. Mihailescu, E. Gyorgy, N. Chitica et al., "A parametric study of the deposition of the TiN thin films by laser reactive ablation of titanium targets in nitrogen: the roles of the total gas pressure and the contaminations with oxides," Journal of Materials Science, vol. 31, no. 11, pp. 2909-2915, 1996.

[6] A. Perrone, "State-of-the-art reactive pulsed laser deposition of nitrides," Japanese Journal of Applied Physics A, vol. 41, no. 4, part 1, pp. 2163-2170, 2002.

[7] S. B. S. Heil, E. Langereis, F. Roozeboom, M. C. M. Van De Sanden, and W. M. M. Kessels, "Low-temperature deposition of TiN by plasma-assisted atomic layer deposition," Journal of the Electrochemical Society, vol. 153, no. 11, Article ID 045611JES, pp. G956-G965, 2006.

[8] R. Krishnan, T. Mathews, A. K. Balamurugan et al., "Reactive pulsed laser deposition of titanium nitride thin film: optimization of process parameters using secondary ion mass spectrometry," Applied Surface Science, vol. 256, no. 10, pp. 3077-3080, 2010.

[9] E. Rauhala, "Proton elastic scattering cross sections of carbon, nitrogen and silicon for backscattering analysis in the energy range 0.7-2.5 MeV," Nuclear Instruments and Methods in Physics Research B, vol. 12, no. 4, pp. 447-452, 1985.

[10] R. Krishnan, R. Ramaseshan, T. Mathews et al., "Synthesis of nanostructured titanium nitride films by PLD through reactive processing," Surface Engineering, vol. 25, no. 3, pp. 218-222, 2009.

[11] E. D’Anna, M. L. De Giorgi, G. Leggieri et al., "Oxidation interference in direct laser nitridation of titanium: relative merits of various ambient gases," Thin Solid Films, vol. 213, no. 2, pp. 197-204, 1992.

[12] M. Mayer, SIMNRA User's Guide, Report IPP 9/113, MaxPlanck-Institut fur Plasmaphysik, Garching, Germany, 1997.

[13] Y. L. Jeyachandran, S. K. Narayandass, D. Mangalaraj, S. Areva, and J. A. Mielczarski, "Properties of titanium nitride films prepared by direct current magnetron sputtering," Materials Science and Engineering A, vol. 445-446, pp. 223-236, 2007.

[14] S. Adachi and M. Takahashi, "Optical properties of TiN films deposited by direct current reactive sputtering," Journal of Applied Physics, vol. 87, no. 3, pp. 1264-1269, 2000. 

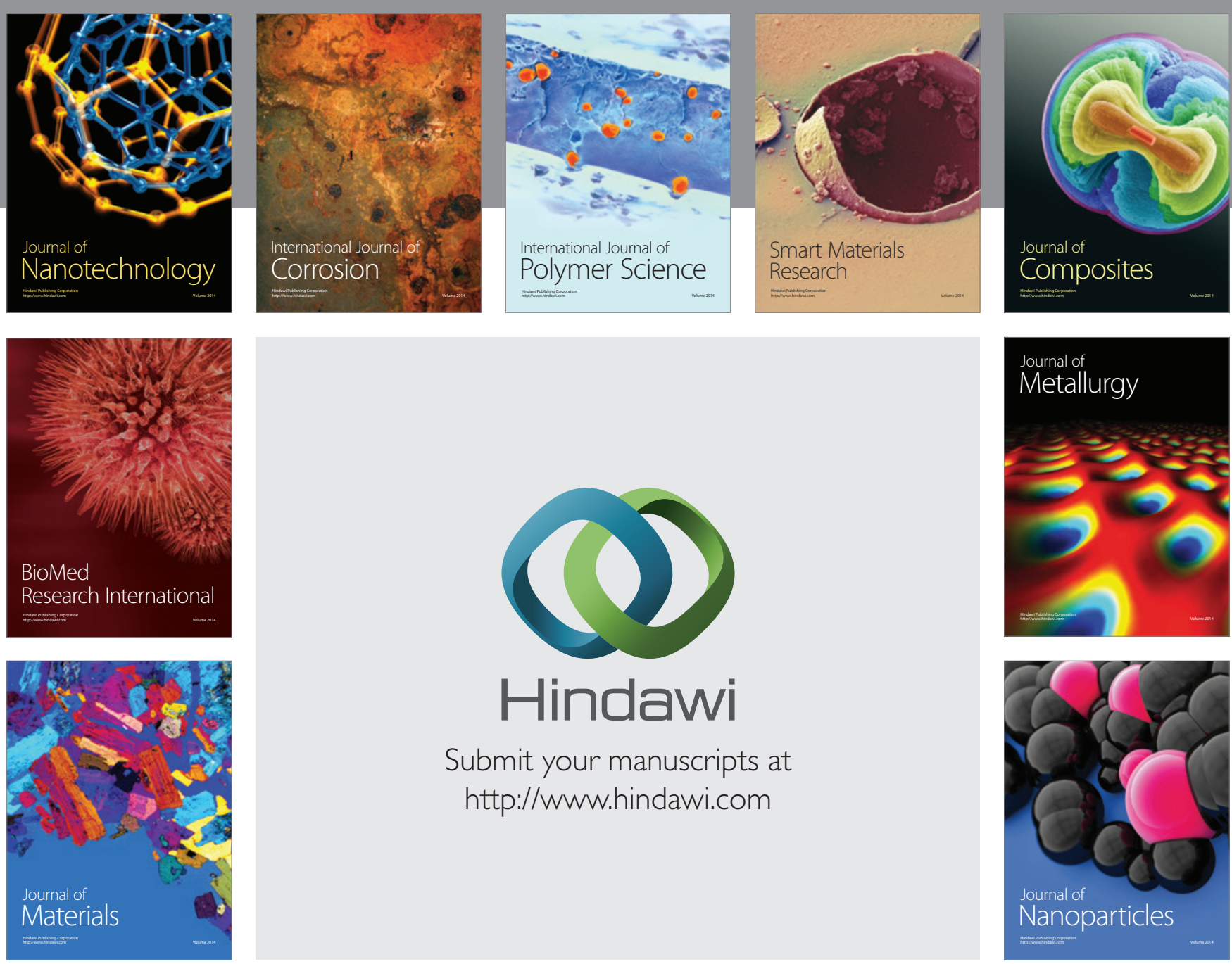

Submit your manuscripts at http://www.hindawi.com
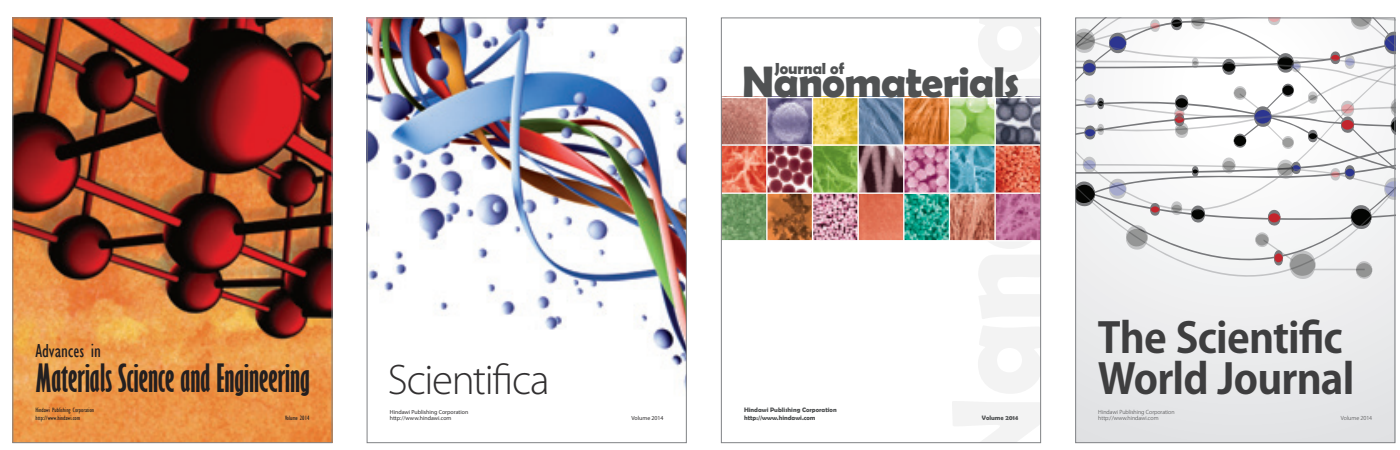

\section{The Scientific World Journal}
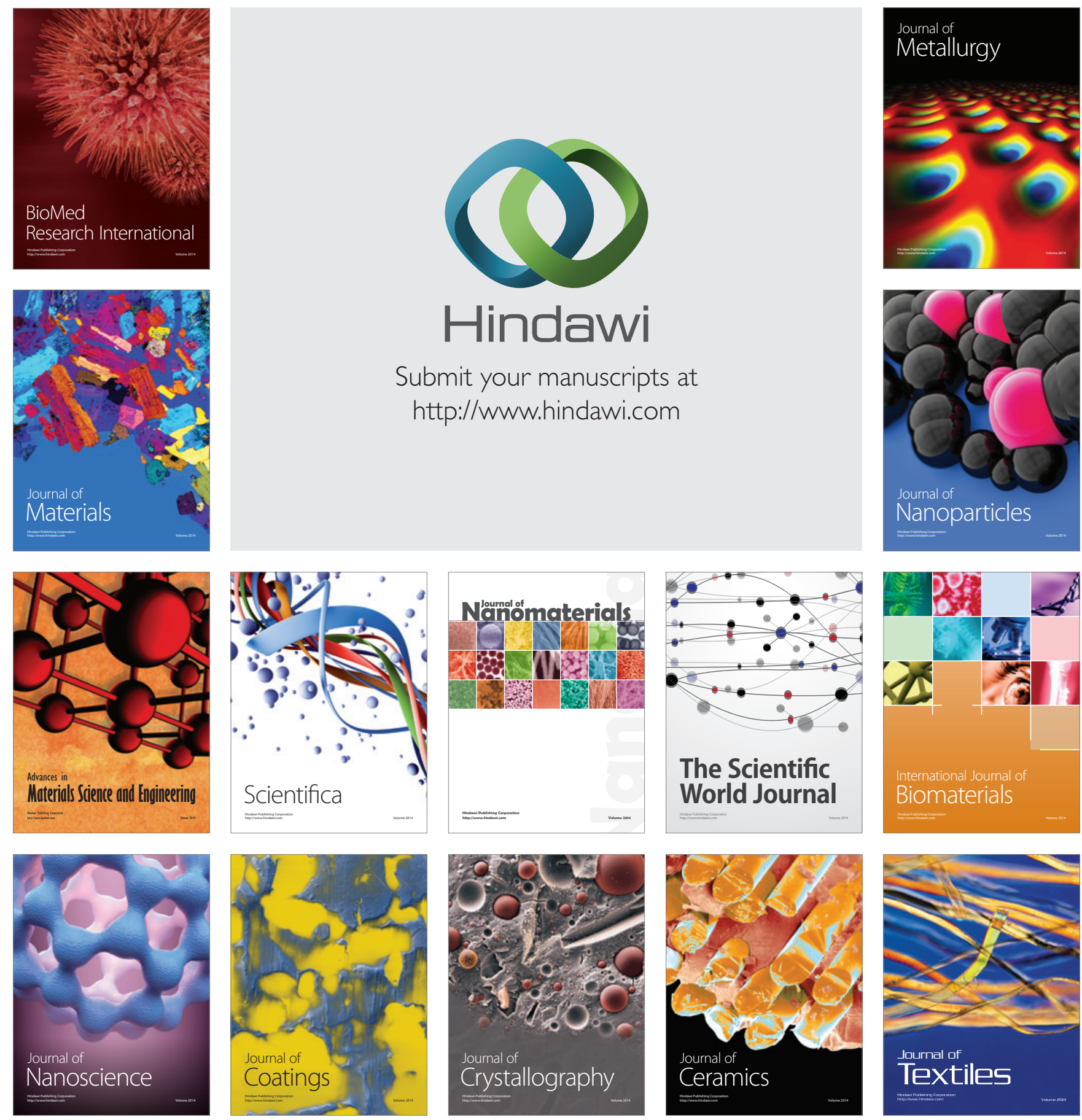